\title{
Evaluating Disaster Risk Reduction Preparedness Strategies in Primary Schools in Kenya: Gaps, Challenges and Implications
}

\author{
Dr Loise Gichuhi \\ Senior Lecturer, University of Nairobi \\ PO BOX 30197-00100 Nairobi, Kenya \\ E-mail: Loise.wambui@uonbi.ac.ke
}

Received: Nov. 7, $2021 \quad$ Accepted: Dec. 4, $2021 \quad$ Published: February 1, 2022

doi:10.5296/jse.v12i1.19255 URL: https://doi.org/10.5296/jse.v12i1.19255

\begin{abstract}
Globally disasters have increased unprecedentedly creating havoc on households and communities despite well-documented awareness levels. Governments and people levels of disaster preparedness have remained unabated in many countries in Africa. However, disasters' impact can be reduced if people are sensitized about fundamental steps and strategies to reduce risks. Documented literature shows that if taken seriously, disaster risk reduction (DRR) measures are likely to cost less compared to the cost of loss of livelihoods, possessions and the cost of managing its consequences including loss of life. Preparing teachers and the schools for disasters is very important in creating sustainable strategies that can be integrated in day-to-day school activities. Using both quantitative and qualitative methods of data collection, this paper presents the evidence on the potential of preparedness and readiness of public primary schools to cope during and after a pandemic. With a sample of 240 teachers and 24 headteachers from 80 schools in 8 Sub-Counties distributed across Kenya, the findings show that the effectiveness of a school DRR mitigation measures can be a great indicator of how a school and its inhabitants: teachers and children can be prepared or not in times of a disaster. Disaster risk reduction strategies must be both supply-driven and demand-driven for buying in and to motivate teachers and learners to avoid disasters. This study brings out what the gaps and challenges are in primary schools in Kenya and suggests what can be done at both national and regional levels to help the schools cope with disasters.
\end{abstract}

Keywords: Disaster Risk Reduction, Teachers, Primary Schools, Policies, Kenya 


\section{Macrothink}

\section{Introduction}

\subsection{Introduce the Problem}

Globally, disasters have increased unprecedentedly creating havoc on schools, households, and communities. Disaster awareness is well documented but preparedness for disasters has remained unabated in many countries in Africa. Education and learning have a fundamental and unquestionable role in enriching people's lives through raised aspirations, set values and the multiplier effect across generations. Education as a fundamental human right and an enabling right is likely to suffer if disasters are not mitigated in good time and with the right resources and speed. Children, irrespective of their gender, age, social-economic, cultural, and religious diversities must be protected from the vulnerabilities of disasters. Disasters can exacerbate education inequalities and can create vulnerable children dropout off mainstream education. This would create human capital potential waste that could derail the progress of Sustainable Development Goals (SDGs) and in particular, SDG 4, Target 4.1 and 4.5 stipulates that all children must complete primary and secondary education of sufficient quality to ensure that they have inclusive, equitable, relevant and effective learning outcomes. Countries are urged to provide schools that are safe, offer child protection, and to include disaster risk reduction in all school curricula (Global Platform for Disaster Risk Reduction, 2009). The adoption of 'The Right to Education in Emergency Situations' (A/64/L.58) in 2010 reinforced child protection and safe schools, and urged the Member States to design and implement education policies that have integral elements of humanitarianism. Governments need to ensure education systems are better prepared to respond to disasters. UNESCO IIEP (2011) documented that the world's $40 \%$ of out-of-school children live in conflict-affected countries, and 175 million estimated children per year are likely to be affected by natural disasters between 2010 and 2020. ISDR (2012) (Note 1) reports 38,000 students and 1,300 teachers, and 3 education personnel were killed, while in the Sichuan earthquake, approximately 10,000 students were crushed in their classrooms and more than 7,000 school rooms collapsed. This disturbing statistic demonstrates the need to design and develop strategies to mitigate the risks and create cost-effective and sustainable education systems and livelihoods among the citizens. The role of education in mitigating disasters cannot be underestimated. Disaster preparedness allows schools and teachers to safeguard lives and create safe environments for learners' otherwise reactionary steps are not cost-effective.

The emergence of the Covid-19 pandemic has worsened the schools' vulnerability and has made many governments less able to respond effectively. With 1.6 billion children and youths affected by school closures (UNESCO 2020), there is a need to have disaster management frameworks in schools and to try to mainstream DRR strategies to minimize the risks. Kenya, for many years, has been experienced a variety of disasters of different magnitude such as droughts, floods, drug abuse, fires, landslides, HIV/AIDS, human conflicts, traffic accidents, terrorism, and the current Covid19 health pandemic. 


\subsection{Purpose of the Study}

The purpose of the study was to evaluate disaster risk reduction preparedness strategies in primary schools in Kenya. To carry out the purpose of the study, the specific objectives are to:

- Find out the level of disaster management awareness of primary teachers

- Identify disaster risk reduction preparedness strategies available in primary schools

- Assess the effectiveness of the strategies in disaster management in primary schools.

- Examine ways school facilities are modified to mitigate disasters

\subsection{Justification of the Study}

Since children and teachers are in school most of the time, the learning environment must be safe from all kinds of disasters. The challenges of both natural and man-made disasters have been happening in schools worldwide, with devastating impact. The immensity and harshness depend on the level of disaster preparedness and mitigation strategies already put in place. This may differ from one country to another. The resilience of a country towards disasters depends on; timeliness on infrastructural support and teachers' response and resilience skills in school. Teachers are the first disaster responders in case of a disaster in schools though they find DRR as an extra burden adding to an already burdening curriculum (Note 2). Therefore, any decision made before and when disasters occur have an impact on learners and policy makers must evaluate the contexts and circumstances before, during and after a disaster in order to circumvent any unavoidable loss. Kenya has emergency planning frameworks and evacuation procedures as well as contingency plans for schools, in disaster management that include: a manual for school safety; an integrated DRR in the curriculum, and sensitization of school managers. Despite these governments' efforts, disasters have continued to happen and the casualties are always students. What is the level of preparedness and where are the gaps in DRR?

\subsection{Related Literature Review}

Education is a fundamental human right that is underlined under SDGs and SDG4 in particular: inclusive and quality education for all. Every child has a fundamental right to be protected and a right to a dignified life (Note 3). According to Ilan (2007), school is not just the product or object of a specific building or a specific place, but it is instead a process by which education takes place in a formalized social setting. Safety must be available at all times and in all the contexts the learners are involved (on-site and off-site) (Ilan 2007). Bastidas and Petal (2012) reviewed 81 countries' existing reports about school safety, and analyzed school practices and concerns and provided recommendations. Some of the recommendations were: school personnel and administrators had a significant role in making schools safe for children, making continuity plans in the case of natural hazards, practice for expected disasters, development of school personnel's response skills, and annual disaster simulation drills, holding regular disaster management or safety committee meetings, and continued maintenance of school physical infrastructure. Between 2007 and 2011 (Note 4) 
5,700 school structures had fire incidents reported in educational facilities in the US where 71 percent affected K-12 schools, and about $50 \%$ of them were as a result of arsonists while the other half were as result of malfunctioning heating units or chemistry lab activities. A study by Akali et.al (2011) in Kenya revealed inadequate disaster preparedness in secondary schools, especially fires disasters. The study reported few Secondary schools to have fire fighting extinguishers in offices, laboratories, stores, and in the kitchens and if available, they are old and sub serviced (Akali et.al 2011). This resonates with many schools, especially in Nairobi, that have fire extinguishers that are as old as the schools, some more than 60 years old (Note 5). The fire extinguishers are "hardly checked (QASO discussions in a seminar, 2018) and sometimes the QASO mission is mainly curriculum standards due to time constraints and the geographical scope needed to be covered". Since disasters can happen at any time to any one, everyone in a school setup should be prepared to handle and respond safely and effectively (Note 6). Understanding the importance and need for training has remained the biggest hurdle in emergency contexts and especially formalized training on DRR. During emergencies everything can be very complex, and responders' level of response is tested to the core. Prior training plays an important role before, during and after an emergency. To avoid disaster reactive strategies, schools should prioritize disaster preparedness and set safety budgets on training school communities. It is noted that quality assurance inspection of schools' standards, many times concentrate on curriculum issues and not disaster-related factors like infrastructure, WASH, or enough classroom spaces (Njoroge 2008). Some schools hardly have enough space to accommodate all the learners in classes, dorms, and dining halls. This contributes to the vulnerabilities if a disaster occurs (RoK 2007).

The government (RoK, 2001), through Ministry of Education Circular No G9/1/169 (Note 7) has continued to stress the need for school safety in Kenya. The circular sets instructions for maintaining safety in schools:

- Headteachers should reside in schools;

- Fire drills should be held at least twice every year

- Emergency doors should be created in dormitories and special rooms

- Safety instructions should be prominently displayed in laboratories and workshops

- Prevention of overcrowding in classrooms and dormitories

- Classrooms should be built upwind from laboratories, kitchens, and playgrounds and their longer sides to run in an east to west direction;

- One toilet to be provided for every 30 students and wholesome water to be provided for consumption by students

- Demarcated school grounds with proper fencing and secure gates

- Dormitory windows should open outwards and be without grills

- Dormitories should have double doors opening outwards 


\section{Mll Macrothink}

- Firefighting equipment should be provided; regular painting and whitewashing of buildings

- Involvement of registered professionals in site planning, design, construction, and maintenance of school buildings;

- Regular health inspection of premises and students

The Safety Standards Manual for Schools (Note 8) further states that the school management/board should be more proactive in creating mechanisms and procedures that ensure the school community are sensitized on measures and steps required to reduce the occurrence and impact of disasters. The ministry of education emphasizes the need for continuous monitoring and spot checks of the school compound to ensure students are safe even at night (Ministry of Education, 2008). Despite an elaborate checklist, schools in Kenya have continued to experience disasters.

Overtime, Kenyan schools have faced serious catastrophic disasters in schools: some of the notable events are when Bombolulu secondary school dormitory caught fire and 26 teenage girls were burned to death. Overcrowded dormitory (Note 9) as well as a door to the dormitory being locked from the outside and all of its 10 windows being barred, was indicated as the major factors that led to death (Oduor 2012). Bombolulu burnt dorm didn't have fire extinguishers and the girls died as they tried to escape through 2 narrow doors. The list of other schools affected by emergencies is many (Note 10) in Kenya. In 2001, 58 students from Kyanguli mixed secondary school, in Machakos County (Note 11) were burnt to death after a fire razed their dormitory where 28 others were seriously injured. In 2012, 8 pupils of Asumbi girls boarding Primary School in Homa Bay County died after a fire razed their dormitory believed to have been caused by an electrical fault. The dormitory that had no emergency exit, also had its windows grilled with wire mesh and is said to have been locked from outside making it hard for the pupils to escape or get immediate help (Note 12). There are certain standards and regulations that we must ensure are upheld and we must hold our institutions accountable as well to ensure the safety of the children. A fire broke out in Moi Nairobi and 7 girls lost their lives and 16 were hospitalized with two in critical condition (Note 13) Why can't we, as a country, learn from past tragedies and protect our children? The dormitory was designed to host 80 girls and a few alterations were done to house 300 students (Note 14).

\subsection{Impact of Covid19 Pandemic on Education}

Since March, 2020 when COVID-19 pandemic was declared a global pandemic, partial or full school closures have affected many students and many others are likely to fall below the minimum proficiency level in reading as a result of the health crisis (Note 15). With the Covid19 pandemic, school closures have brought significant disruptions to education across Kenya in the better part of 2020 safe for phased out reopening in October 2020 to examination classes (MoE, 2020) and all the other classes in January 2021. This emphasizes that health pandemics have a ripple effect on other sectors; education has suffered its share of challenges. School closures caused by the health pandemic aggravated previously 


\section{Macrothink}

documented inequality gaps and those children who were already vulnerable of being excluded from a quality education equation have a high chance to be most affected (Note 16) and majority of parents assumed teaching can only happen in class and children must be in a four-walled space and have a teacher (Note 17). As countries continue to respond to COVID-19 pandemic and school crisis, many of them are challenged by keeping the schools and colleges open and how to maintain standards in the midst of health protocols. UNESCO established the Global Education Coalition (Note 18) to mobilize and support learning continuity, in 3 central themes: Gender, connectivity, and teachers (Note 19). Preparedness of these 3 major ingredients is not an option if member countries are to address the learning gaps and vagaries of Covid19.

\section{Methodology}

\subsection{Research Design}

This study is based on a mixed-method descriptive research design to understand DRR preparedness strategies in primary schools in Kenya. It involved a combination of both quantitative and qualitative approaches. This design helps the researcher to identify gaps, challenges, and implications and it also allows the researcher to use both qualitative and quantitative methods to draw conclusions and recommendations that can be useful in disaster management policy frameworks and implementation.

\subsection{Sampling frame and sample size}

In selecting participants for the study, a combination of random, multistage, and purposive sampling was employed to ensure the voices of all relevant respondents are captured. The population of the study is drawn from 4 counties that are purposely selected due to perennial reoccurrence of disasters; Nyanza, Turkana, Baringo, and Nairobi (informal settlements). The Sub-Counties within the Counties are treated as homogenous and therefore, representative Sub-Counties are randomly picked. Subsequently, 2 Sub-Counties are picked from each County to make a total of 8 . To get the unit of analysis; a two-stage stratified sampling methodology was used to select the primary schools from the sampling framework of schools in the targeted study Sub-Counties. This involved determining the number of schools for each Sub-County followed by sampling the primary schools in each sub-county. In stage1, the sample size for the Sub-County was determined using a proportionate size of $10 \%$. In stage 2, a systematic random sampling technique was used to select 10 schools for each Sub-County. Starting from the first school every kth school in the sample frame was selected; where " $\mathrm{k}$ " is the sampling interval calculated as $\mathrm{k}=\mathrm{N} / \mathrm{n}$ where " $\mathrm{n}$ " is the sample size and " $\mathrm{N}$ " is the population size. In each of the 80 schools targeted, purposeful sampling was used to select 5 teachers ( 1 headteacher, 2 females, and 2 males) to give a total of 400 participants. Three hundred and twenty teachers were targeted for the questionnaire while 80 headteachers were to do an in-depth interview. 


\subsection{Data collection, processing and analysis}

For quantitative data, the study used an online questionnaire, which was transmitted through a Google form and telephone interview/conversations for qualitative data. These methods were chosen because of the sensitivity of the covid19 period that restricts visitors to go to schools unless permitted by the Cabinet Secretary, Education, and also in observance to the Ministry of Health protocols to keep social distance and to avoid, where possible, paperwork. In addition, the use of the online tool has the benefits of access to participants in difficult to reach locations and the cost-effective nature of having automated data within a shorter time and effort. Many researchers have adopted these methods noting that Virtual communities have flourished online, and hundreds of thousands of people regularly participate in discussions about almost every conceivable issue and interest (Horrigan, 2001; Wellman, 1997). However, online interviews have their disadvantages. Online survey research and virtual telephone interviews have the limitations of uncertainty over the validity of the data and sampling issues, and lack of face-to-face interactions can enhance fallsification that may lead to unreliable data. Interviewees may choose just to respond with what they think is the right answers or what the interviewer wants to hear (Note 20).

\subsubsection{Response rate}

The findings of this paper are analyzed thematically and also using descriptive statistics. From a total of 320 questionnaires that were distributed to teachers, the response rate was $75 \%$ (240 questionnaires) and only $24(30 \%)$ out of 80 targeted number of headteachers responded successfully to the interviews, giving a total of 264 participants.

\subsection{Limitations of the study}

Headteachers were not so willing to have an interview citing bad timing, conflicting schedules and also the sensitivity of the research given the health pandemic protocols. Given that the pandemic was still ongoing at the time of the research, headteacher interviews had to be conducted virtually; it was hoped that at least a blended mode might be used, with the researcher able to meet with interviewees face-to-face, but this proved impossible for reasons of health and safety. A small number of participatory focus group discussions to capture some of the experiences and perspectives of teachers were also originally envisaged but unable to go forward for the same reasons. Issues of connectivity in some regions and the competing demands of both headteachers and teachers amidst an ongoing health crisis additionally presented challenges for securing participation and conducting in-depth interviews, despite the goodwill and generosity with their time of those who were able to be interviewed. These limitations narrowed the scope of the analysis and the range of perspectives informing it.

\section{Findings and Discussions}

To be systematic in presenting the findings, the researcher used an objective format to capture all the information collected from the questionnaires and the in-depth interviews. The analysis presented is on: teachers' disaster management awareness; strategies for disaster risk reduction preparedness and their effectiveness in disaster management; and modification of school facilities to mitigate disasters. 


\section{Macrothink

\subsection{Teachers’ Disaster Management Awareness}

The number of teachers who responded about disaster management awareness was 76\% while $24 \%$ reported a lack of awareness. Of the $76 \%$, further probing reviewed that only $39 \%$ have a high-level awareness, $35 \%$ are on average while $26 \%$ categorized as low in awareness.

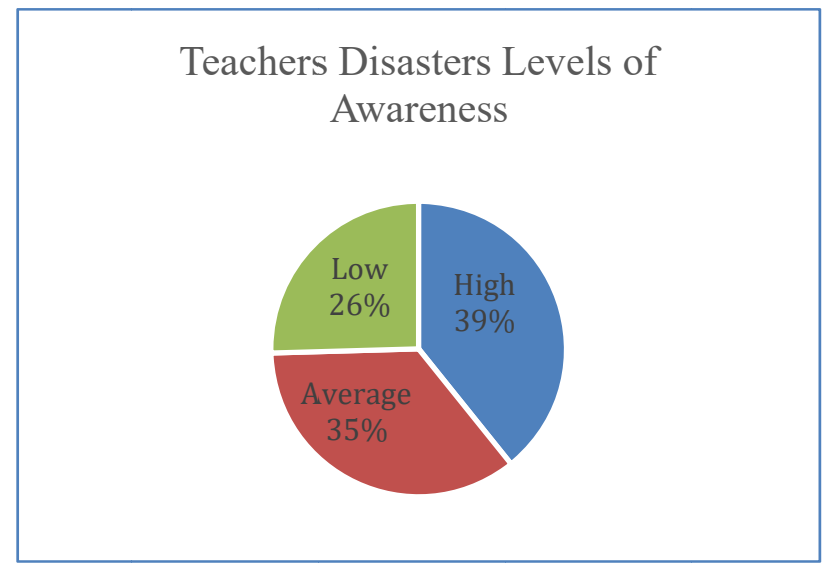

Figure 1. Numbers of teachers aware of the disaster management $\mathrm{N}=182$

The results on the level of disaster awareness by the teachers indicate a worrying trend. If less than $50 \%(39 \%)$ can be said to have a high level of awareness, this cannot be ignored given the teachers' important role in school and with the children most of the time. Teachers must have knowledge and skills and be always prepared to respond to disasters as much as they are with the children. Schools have a protective role and are considered as a safe environment meaning the teachers must have knowledge and skills regarding disaster preparedness and management. When the teachers are aware and well informed about disasters, they can transfer that knowledge to learners and indirectly to the households (Basrori 2013). The role of the teacher cannot be underrated in disaster response.) A teacher with disaster management awareness and skills will not only protect the learner in times of crisis but will also help in integrating DRR into the curriculum (Johnson \& Ronan, 2014). The findings are in line with Joshi (2014), research, which found that among the teachers in India, about 53\%, still have gaps in awareness and their knowledge and skills on disaster preparedness were inadequate. Every teacher must be conversant with disaster management awareness.

The participants were asked to identify the best source of their disaster management awareness information. Figure 1 shows different sources of information 


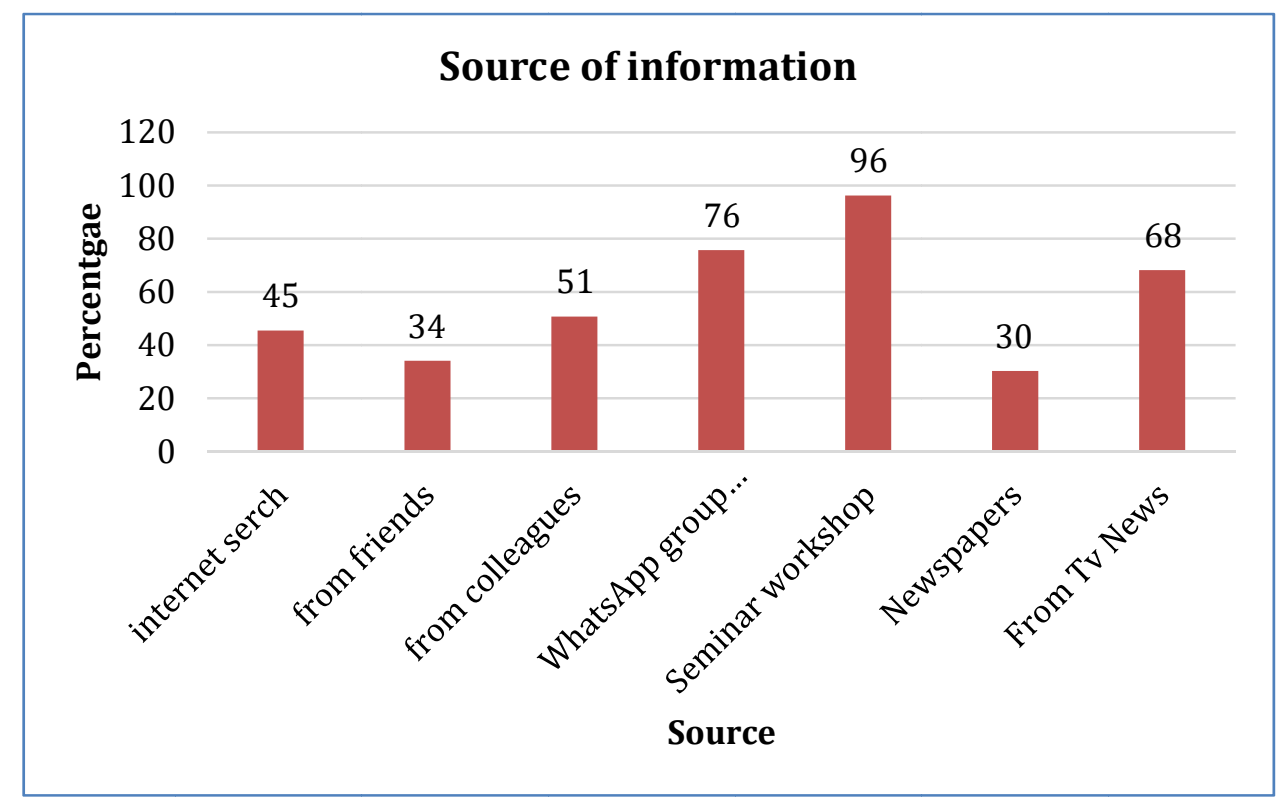

Figure 2: Different sources of information on disaster awareness

From the results in figure 2, the majority, $96 \%$, got the information from seminars and workshops followed by WhatsApp groups sharing at 76\%. The least mentioned source of information is from newspapers at $30 \%$. This may be as a result of lack of access to newspapers or maybe the newspapers do not offer information on disaster awareness. Even though broadcast media are important information sources immediately before and during disasters, only $68 \%$ mentioned TV as a source of information and no radio mention. The education sector should promote awareness through the radio as it has a wide coverage and can encourage general household disaster preparedness and by extension to the children.

Approximately $60 \%$ of surveyed teachers reported that both television and radio are important sources of disaster management awareness but they only report breaking news after the disaster has happened. The broadcast houses are only reactive most of the times

An unnamed teacher from Turkana County

\subsection{Number of disaster training workshops attended organized by the schools.}

According to the findings, $65 \%$ of the principals reported that seminars and workshops on DRR have not been organized in the sub-county while $15 \%$ of principals reported few ones have been organized at the sub-county levels with only $8 \%$ admitting DRR workshops and seminars are frequently organized. This might indicate that disaster awareness and preparedness workshops/seminars may not have been prioritized in the regions or information doesn't reach the target teachers and principals in good time. These results resonate well with Gagliardi, Neighbors, Spears, Byrd \& Snarr (2012) study of 334 teachers working in public 
schools in the USA and found that most of them had a knowledge deficit about emergency care due to a lack of effective and formal emergency care training in teacher preparation programs. Tuswadi \& Hayashi (2014) who also studied 191 teachers in 24 selected primary schools in the Merapi volcano area in Indonesia found that teachers had a lack of knowledge and skills related to disaster prevention due to limited teacher training.

Since the majority of the teachers, $96 \%$ reported getting disaster management information from seminars and workshops, they were asked to confirm how frequently they attend disaster training workshops organized by their schools. This was also to triangulate with the headteachers' findings. Since teachers are supposed to be the first responders in a school, training them on disaster management is important because an inadequate and inappropriate background knowledge, expertise and experience in disaster preparedness can be very expensive in case of a disaster affecting a school or a college.

Table 1. Number of disaster training workshops attended organized by the schools and by whom?

$\begin{array}{lll}\text { Participants } & \% & \text { Who organized } \\ 113 & 43 & \text { Sub-county } \\ 63 & 24 & \text { LNGOs } \\ 60 & 23 & \text { zonal } \\ 25 & 10 & \text { Private Sector }\end{array}$

Less than $50 \%$ of the teachers have attended workshops/seminars organized within the Sub-County. While $23 \%$ of the teachers have attended workshops organized at zonal levels, LNGOs have also contributed to training the teachers. These numbers may not show a clear picture of the workshops attended as in many cases, some teachers would be attending all the workshops organized by different groups. The continued and new emerging disasters like the covid19 pandemic may provide a window of opportunity to bridge the knowledge gaps on disaster management awareness and the challenging working conditions for teachers during the onset of a disaster.

"Since the covid19 pandemic hit the schools and colleges, the public discourse on teachers has changed. Parents and communities have started to appreciate the teachers' role differently. The pandemic has presented an opportunity and opened many stakeholders' eyes to the teachers' role that goes beyond just classroom interactions to the provision of guidance and counselling, extra curriculum support and supplementary value additions knowledge through the Ministry of Health protocols"

An unnamed teacher remarks

Whether disasters exist or not, teachers ' role cannot be underestimated to ensure that students are safe and are taught which is essential to allow for syllabus coverage and achievement of education targets and benchmarks. Government and policymakers and to a great extent 
educational leaders will need to plan to provide teachers with more training and expose them to practical experiences and better working conditions and resources they need to expedite the important mission as educators, which will certainly have an impact on the lives of learners before, during and after a disaster. But time must be created and priorities set to train teachers.

"Many times, training is not prioritized due curriculum activities that constrains the daily commitments, -to get involved in the disaster issues and activities-. The Ministry of Education and TSC must set specific time to train teachers and the frequency of training should know well in advance to accord it the urgency it needs.

\section{A headteacher's remarks}

Disaster prevention and mitigation are important for the continuity of schools because when disasters occur in Kenya like flooding and inter-tribal conflicts, some schools are used as community shelters, preventing them from operating as classrooms. This is important especially with emerging disasters like COVID-19 that have a devastating impact on the education sector; the participants implored the need to have continuous and effective training not only to teachers but to the learners and parents. This will lessen the unavoidable dangers in schools and the communities

\subsection{What kind of disasters' information do the teachers get frequently and from whom?}

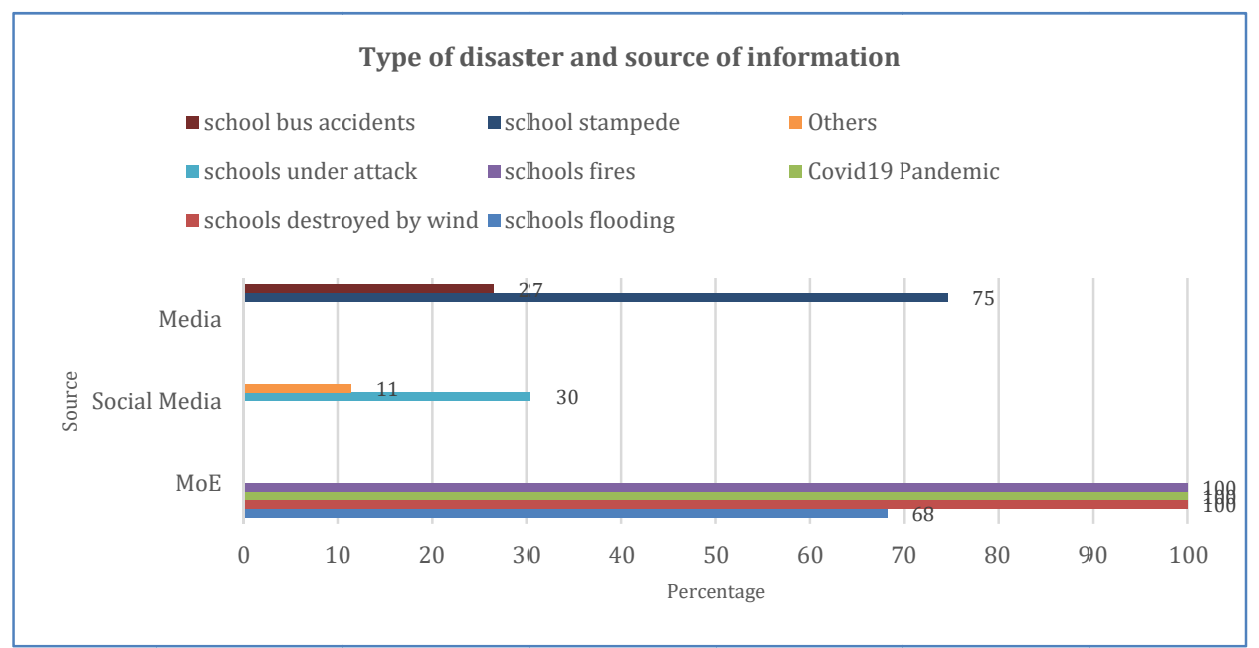

Figure 4. Information on Disasters Teachers gets frequently

From Figure 4, it is evident that all the 264 participants get frequent information on school fires, schools destroyed by wind, and the covid19 pandemic. These are the most frequent school disasters in Kenya apart from Covid19 which is the most current disaster and has affected the education sector globally. The MoE has a rich network to reach all the teachers within a short time. School stampedes, schools under attack, and school bus accidents are not 


\section{Macrothink}

common occurrences and therefore most of the information sources are diversified mostly to social media and other media outlets like newspapers, radios and TVs.

The Ministry of Education should map and collect DRR teaching and learning resources to help the teachers in understanding and implementing disaster resilience strategies in the classrooms and how to keep learners safe from harm before, during and after an emergency or disaster. During a disaster, use of social media increases and if well utilized can be one of the most influential tools for information transmission and real time data for emergency effective and timely response and recovery. The government should look at ways of working and strengthening social media platforms by coming up with usage protocols where possible for the benefit of the disaster response and recovery. During disasters, social media has proved to be effective as it is often the first and only information accessible, and it is provided by witnesses on the ground as the event unfolds (Note 21).

\subsection{Effectiveness of DRR Preparedness Strategies in Disaster management}

The study sought from both teachers and headteachers the DRR preparedness strategies available in the schools. The findings show that most of the schools use reactive approaches. The headteachers reported that they respond to disasters using various strategies; having all the learners' parents' information in the schools' parents register (40\%), calling registers twice a day $(80 \%)$, sensitization of disasters and impact during school assembly $(60 \%)$, during class meetings (30\%), teachers' meetings (24\%), parents Annual General Meetings (20\%), liaising with local NGOs for regular meetings (20\%). Though the teachers didn't agree with all the headteachers' strategies, they, however, reported sensitization is done but in an ad hoc manner. Other strategies that have been used are clearing the bushes and grasses in the school compound, planting more trees to curb the wind disasters, liaising with the local police to curb insecurity, having dormitory custodians' day and night, liaising with the local clinics and hospitals to sensitize on health protocols, each class to have a disaster reduction motto every year and encouraging inter-house competitions on DRR themes every year. Eighty per cent of the teachers reported a lack of preparedness strategies and the schools are only reactive to disasters. The teachers reported the availability of disaster preparedness manuals but no training has been done on the best method of implementation. 
Table 2. Disaster risk reduction preparedness strategies

\begin{tabular}{|c|c|c|}
\hline Strategy & $\begin{array}{l}\text { No. of teachers } \\
\text { and headteachers }\end{array}$ & $\%$ \\
\hline Parents information in a parents register & 100 & 38 \\
\hline Calling registers twice a day & 264 & 100 \\
\hline Frequent sensitization on disasters & 56 & 21 \\
\hline $\begin{array}{l}\text { Liaising with NGOs for information and } \\
\text { training }\end{array}$ & 40 & 15 \\
\hline $\begin{array}{l}\text { Clear the bushes and grasses in the school } \\
\text { compound }\end{array}$ & 124 & 47 \\
\hline $\begin{array}{l}\text { Planting more trees to curb wind disasters } \\
\text { A boarding facility for children coming }\end{array}$ & 56 & 21 \\
\hline from far & 36 & 14 \\
\hline Liaising with police to curb insecurity & 185 & 71 \\
\hline $\begin{array}{l}\text { Having dormitory custodians' day and night } \\
\text { Liaising with the local clinics and hospitals }\end{array}$ & 36 & 17 \\
\hline to sensitize on health protocols & 264 & 100 \\
\hline $\begin{array}{l}\text { Each class to have a disaster reduction } \\
\text { motto }\end{array}$ & 150 & 57 \\
\hline $\begin{array}{l}\text { Inter-house competitions on DRR themes } \\
\text { every year }\end{array}$ & 184 & 70 \\
\hline $\begin{array}{l}\text { Sensitization in education disaster } \\
\text { policies and guidelines }\end{array}$ & 264 & 100 \\
\hline Enhancing washing of hands & 264 & 100 \\
\hline Wearing of masks & 264 & 100 \\
\hline Avoiding overcrowding classes & 120 & 45 \\
\hline Limiting visitors coming to school & 160 & 60 \\
\hline No visiting days for boarders & 36 & 17 \\
\hline Limiting food coming to school & 204 & 77 \\
\hline Information backup (from headteachers) & 06 & 2 \\
\hline $\begin{array}{l}\text { Display of emergency contact information } \\
\text { in case of a disaster }\end{array}$ & 264 & 100 \\
\hline
\end{tabular}

The findings reveal that all the participants $(100 \%)$ call the registers twice a day; they enhance washing of hands although some teachers cited lack of regular water supply in many schools (56\%), wearing of masks and having sensitization on disaster preparedness guidelines and policies. Display of emergency contact information in case of a disaster and liaising with the local clinics and hospitals to sensitize on health protocols was also mentioned by all the participants. We note that these are policy-driven strategies and are currently being implemented strictly due to the Covid19 pandemic situation. Even though avoiding overcrowding classes, limiting visitors in schools and no visiting days for boarders, these are 
not observed by all the schools as the results show. Parents' information register is important in a school to ensure that they have clear and accurate information about what is happening in a school environment. This becomes critical especially during a crisis because of learner-parent matching and tracing. From the findings it is only $38 \%$ of participants who mentioned that they have parents' information register and the majority $(70 \%)$ of the headteachers interviewed reported that the register is not frequently updated and is only updated every quarter or if the information is needed elsewhere. From head teachers' responses, parents' registers only have names of 1 parent/guardian and telephone numbers.

"During this time of Covid19, we have found it very necessary to keep updated data, with 2 or 3 alternate numbers that can be used during an emergency. We are particularly interested with WhatsApp numbers as the easiest method of reaching the parents/guardians through formation of parents/guardian WhatsApp groups"

An unnamed headteacher from Nairobi

Frequent sensitization of disasters was only reported by $56(21 \%)$ of the participants. This is low considering the catastrophic impact disasters may have on a school. Scheduling of curriculum activities, time factor and methodology used to sensitize teachers were mentioned as a challenge where the majority $(88 \%)$ reported the importance attached to syllabus coverage to the expense of other important activities in the school. Cascade method used to sensitize teachers, though being cost-effective and reaches many teachers within a short time, was reported as a not ineffective method for teacher professional development (TPD) and the teachers feel the information flow diminishes at various levels (Pryor et al, 2012, Gathumbi et al, 2013, Dadds 2014).

It is imperative to note that these strategies need serious enactment, finance and follow-up. Policy enactment and implementation have a life span and are tagged on various factors. In many situations and economies policies do not fail or succeed on their own merits; rather their progress is dependent upon the process of implementation. Hill and Hupe (2014) noted that lack of bottom- up approaches to policy implementation in favor of the normatively attractive top-down stands on 3 assumptions: a chronological order in which expressed intentions precede action; a linear causal logic whereby goals determine instruments and instruments determine results; and a hierarchy within which policy formation is more important than policy implementation. This, according to teachers in this study, ignores them during formulation and design and is only involved in the implementation. Sixty eight percent of teachers think the top-down policy implementation strategies are only going to succeed if they are accompanied by some independence of the context-related factors and as long as there are budgetary allocations. 
"Covid19 has brought in several costly demands that are not financed or budgeted by the government"

An unnamed headteacher's remarks

The majority of teachers $(76 \%)$ are aware that the government has already put in place policies and frameworks for the education sector in general, but are not contextualized to specific sub-sectors or groups of people. Specific interventions should, therefore, focus on making these policies targeted to ease their implementation at various levels.

"Even when guidelines and plans are developed, little is done by way of targeted dissemination and sensitization. For example, it was reported that despite the recent publication of National Guidelines for School Re-entry in Early Learning and Basic Education (2020), only very few headteachers and parents are actively following and implementing the policy",

A teacher from Nairobi, Informal Settlements

Some schools are disproportionately underdeveloped in terms of infrastructures and implementing some of the Covid19 health protocols is a tall order in the short term. Therefore, it is important to understand that any policy formulated at the national level is likely to have implementation inconsistencies at the sub-national level (and school level) especially when the Sub-national level enjoys some degree of political authority (Norris et al. 2014). In Kenya, Counties are endowed differently in terms of social-economic factors. Implementing some policies especially where parents are presumed to play a part in infrastructure development may be a problem, the context may demand re-prioritization. Braithwaite et al. (2018) and Allcock et al. (2015), noted that even in a centralized governance structure, implementation is locally contextualized. It is not a magic bullet that any successful intervention can work in all situations.

"We have very good disaster management plans in Kenya, but do we implement plans that are inclusive in schools in remote regions?"

A teacher in West Pokot

\subsection{Data Recovery Plan}

Government agencies must have personnel and resources dedicated to data for disaster planning and management. In disaster response and reconstruction, providing responders and policy makers with relevant, reliable and timely data is a major priority to ensure resources is distributed evenly and timely to the targets without bias (Note 22), Well collected and 


\section{Macrothink}

managed data before a disaster happens, benefits effective preparedness and response and ensures well targeted help to the beneficiaries. Moreover, due to the nature and severity of the disaster at times, backup of information becomes cost-effective and allows an organization to recover quickly from a disaster. This, therefore, should form a part of disaster recovery plans. From the results, only $6(25 \%)$ of the headteachers who were interviewed reported having a backup data plan. When probed further, the headteachers reported having photocopied backup files for the most important school documents like title deeds and logbooks. Unfortunately, the copies are just within the headteachers' offices. Only one headteacher said he has the copies at home. The majority $(98 \%)$ of the headteachers mentioned cloud storage that allows data to be converted to electronic data sets and remotely maintained, managed and backed up, but only $30 \%$ have implemented the strategy. The $2 \%$, though aware, about cloud storage, mentioned electricity and connectivity challenges that would prevent information management in the short run. This is a knowledge gap that should be addressed in disaster preparedness to avoid costly losses. Since disasters are unpredictable, a school needs to back up all the information to avoid the risk of losing everything in case of a disaster. Lack of timely data and information is likely to cause a delay during the response phase. This can exacerbate the vulnerabilities in schools.

\subsection{Knowledge of policies and guidelines on disasters}

The study seeks information on 5 DRR context-related standards, manuals and policies The teachers and headteachers were asked if they have heard or used the following policy guidelines:

- Safety Standards Manual for Schools in Kenya (2008) (Note 23)

- Education Sector Disaster Management Policy (2017),

- National school re-entry guidelines (Note 24),

- Kenya Basic Education COVID-19 Emergency Response Plan (May 2020) (Note 25)

- Guidelines on Health and Safety Protocols for Reopening of Basic Education Institutions amid COVID-19 Pandemic (September 2020) (Note 26)

Figure 5 and figure 6 show results for teachers and headteachers respectively. 


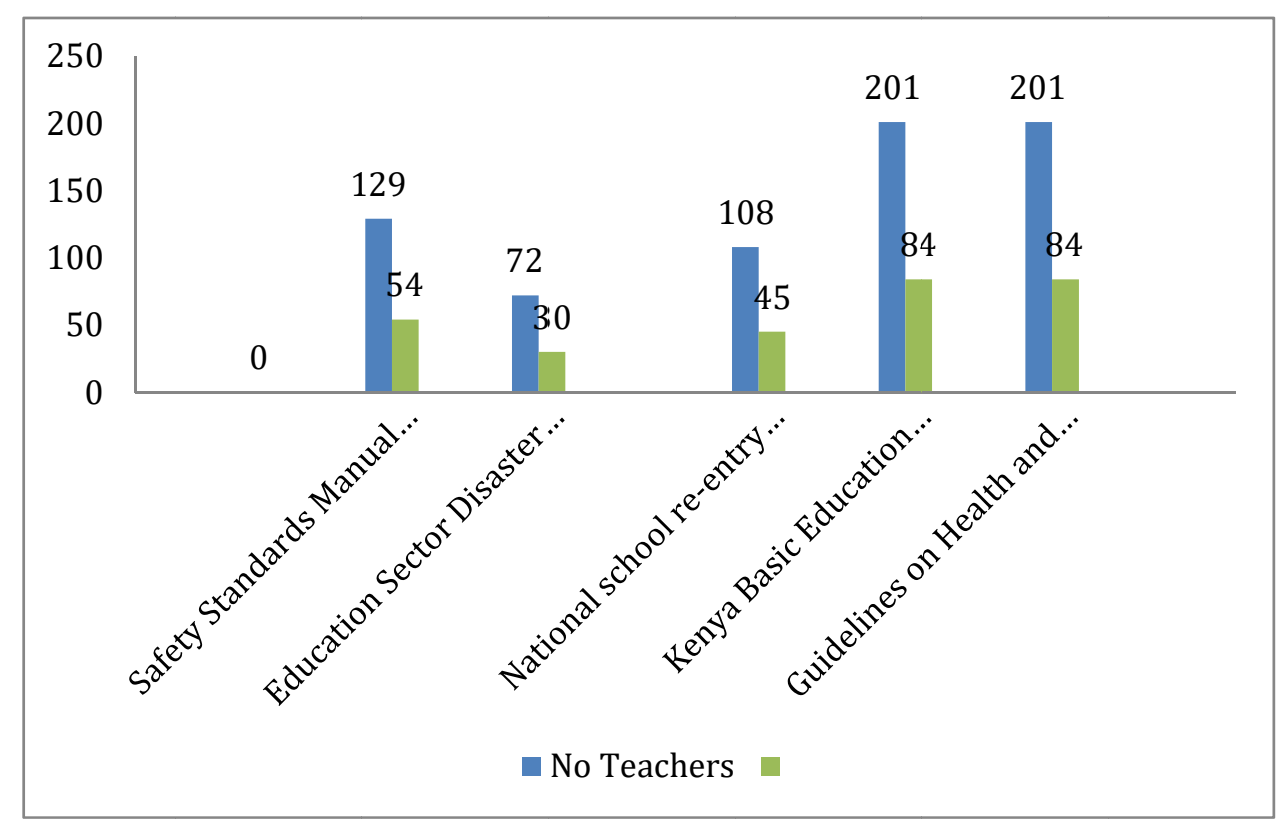

Figure 5. Teachers' knowledge of policies and guidelines on disasters

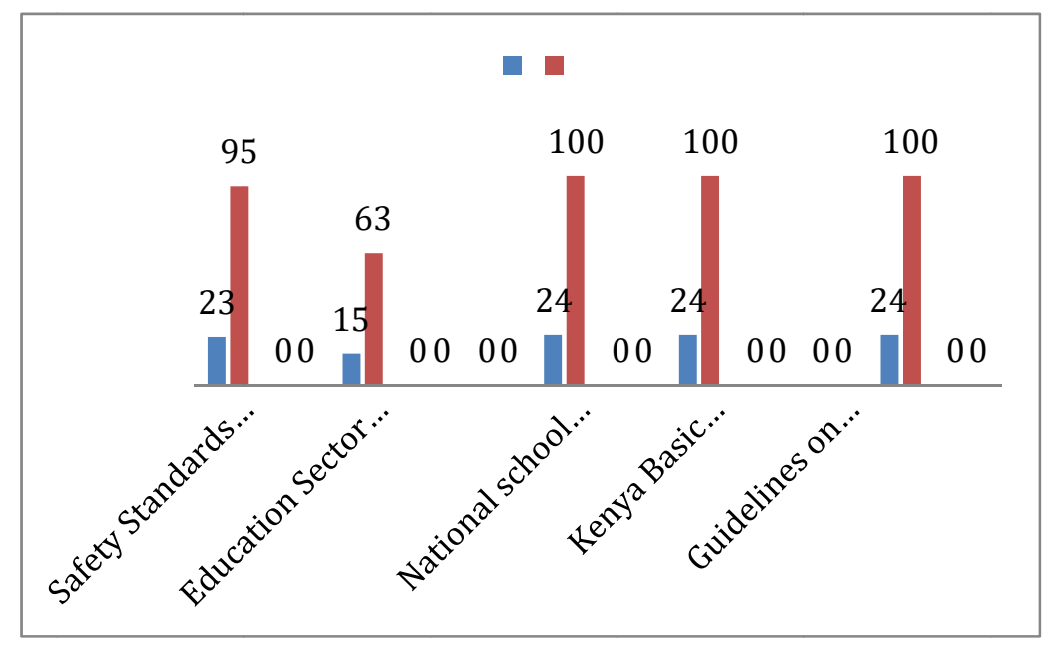

Figure 6. Head teachers' Knowledge of policies and guidelines on disasters

Safety Standards Manual for Schools in Kenya (2008) was prepared after the Post-Election Violence (PEV) in early 2008 when Kenya experienced post-election violence, that left over 300,000 people displaced, many of them schoolchildren. Many schools' infrastructure was destroyed and others closed, disrupting learning for a period of time. The manual outlines the steps to be taken when handling emerging disasters and contexts that disrupt learning. The knowledge of the existence of the manual was stated by $54 \%$ of teachers and $98 \%$ headteachers. However, knowledge of its existence doesn't translate to its usage. In addition, the Education Sector Disaster Management Policy (2017) provides for the establishment of effective mechanisms for coordinated disaster risk reduction interventions and management in learning institutions. As a guide for the effective implementation of disaster management, the policy emphasizes continuous monitoring and evaluation of schools to cushion against any unprecedented disaster. According to one participant, 
"This policy is not disseminated in many counties. Majority (97\%) of the teachers are unaware of this policy and the headteachers only got to hear about it in a headteachers' conference. Most of these manuals and policies remain in our shelves and some in cartons as dissemination is never done. They beautify our offices"

An unnamed Headteacher

All participants were unanimous on the need to safeguard the gains already being witnessed in the education sector. However, despite the benefits, and the huge financial obligations to the government, parents and development partners, access, retention, transition and completion of basic education have remained a challenge. The headteachers lauded the national school re-entry guidelines (Note 27), which are gender-neutral, focusing on improving retention, by reducing or eliminating school dropouts due to various reasons; early pregnancies, early and forced marriages, drug and substance abuse, HIV and A record-keeping cultural practices, child labour and PWDs. However, the headteachers noted the success of the policy lies in government enforcement and how stakeholders collaborate, particularly parents collaborating.

"Early pregnancies, early and forced marriages, drug and substance abuse, child labour and PWDs are so much dependent on the community and parental attitude on how to deal with inhibitive cultural practices"

An unnamed headteacher from Turkana County

Since the onset the Covid19, the response strategies, Kenya Basic Education COVID-19 Emergency Response Plan (May 2020) (Note 28) and Guidelines on Health and Safety Protocols for Reopening of Basic Education Institutions amid COVID-19 Pandemic (September 2020) (Note 29) are well known by the participants. According to teachers (84\%), welcome the guidelines but express difficulties in implementation due to inadequate infrastructure: lack of enough spaces for social distancing, lack of water, children failing to wear masks at all times, the environment where children leave contradicts the $\mathrm{MOH}$ protocols and sometimes the children remain confused on the way forward. However, about $68 \%$ of headteachers were optimistic about the covid19 situation and the use of MoE guidelines and the implementation strategies. 
"But not all what is on paper is implementable, financial allocations may need to be reviewed and create new vote heads to accommodate the emerging issues facing the education sector".

An unnamed headteacher from Nairobi County

\subsection{Modification of School Facilities to Mitigate Disasters}

Since children spend more time in school than anywhere else during the school term, it is important to make the learning environment safe from any kind of disaster. Regular inspection of school facilities enhances conformity to the standards and mitigates any emerging dangers. Numerous students have faced fatal accidents because of weak classrooms that are constructed without the agreed quality parameters. A school in Nairobi collapsed and 8 pupils died and 69 were injured after a classroom collapsed (Note 30). Despite some parents and school neighbours' having raised concerns over the safety and stability of the building, no action was taken. The disaster occurred due to the classroom floors made of wood and on its slab held together by wire mesh (Note 31). Another deadly school stampede in Kakamega, Kenya, left 14 children dead when the bell rang signaling home time. The school's narrow staircase from the third floor made the situation worse. The pupils stumbled and fell on each other as they pushed out of the building (Note 32). All the headteachers in the study agree that schools must be inspected and standards maintained, to avoid catastrophic challenges that are expensive during disasters. Fifty-six per cent (56\%) of the headteachers and $80 \%$ of teachers reported that schools do not have either evacuation plans in case of a disaster or assembly areas like fire assembly points that can hellp in the immediate response to a disaster.

"Lack of fire assembly point in an onset of a disaster where order is difficult to follow, it is something they are considering urgently and especially with the wake of covid19 pandemic"

A headteacher in Nairobi, Informal Settlements

Additionally, water points, toilets and playfields are prone to disasters, especially during health and lunch breaks. To avert any danger, the participants pointed to the need to have good planning and order that have timelines and are inclusive. Teachers (24\%) who teach in the integrated schools reported that these are disaster zones. Many children especially the young and those living with disabilities are disadvantaged when the resources are few and there is overcrowding. 
"Children with disabilities are many times ignored and sometimes they are time-barred to report back to class. We sometimes use peers to enhance order especially for those living with disabilities".

An unnamed teacher from Turkana

Most schools do not have emergency clinics but they keep first aid kits with all the necessary medicines and other requirements. This according to participants (75\%), is not the most ideal given sometimes there are acute medical cases that require medical attention. According to participants, severe medical attention is referred to the local clinics for further management, but most schools face transport logistical problems. All the headteachers agree that the covid19 pandemic situation has taught them the need to have medical cases addressed in schools or nearby clinics urgently. According to Safety Standards Manual (Note 33), the school should post "no trespassing" and "visitors report to the head teacher's office "signs at the main gate entrance. The data shows that $75 \%$ of schools had a sign at the gate while in $25 \%$ of schools without a gate and a fence, a sign was posted next to the main passageway into the school with the same words.

Other requirements reported by both the headteachers and teachers were vetting and management of school visitors. Identification must be done to ensure only authenticated documents are used. School grounds are well kept and are located in places with the least hazards such as floods, wind effects and similar natural hazards and can be leveled up to make them easier for use by all learners and teachers. In the wake of covid19, the Ministry of Education requested all the schools to constitute a safety school committee to monitor the safety of students and teachers. From the study, schools with Functional School Safety Committees were $78 \%$. The $22 \%$ of schools with no committees were dormant and parents participation was minimal.

\section{Conclusion}

In evaluating disaster risk reduction preparedness strategies in primary schools in Kenya, this study brings out the importance of preparing a broad range of preventative actions and strategies that can be taken to prevent or minimize terrible losses of livelihoods, destruction and even life. Teachers are the first responders if an emergency occurs in a school. They must ensure the environment is safe for all the children and themselves. With the emerging disasters and devastating impact of disasters on education, the study highlights the gaps, challenges and implications in disaster risk reduction preparedness strategies in primary schools. Some of the gaps and challenges are systemic and inherent issues that have remained unattended for a while by either the national government or by government departments; policy design and development is a good example. Very many policies are neither implemented nor disseminated and this according to the teachers is a major gap in their day-to-day life and practices in schools. Many teachers discover that they had information after the disaster has happened and somebody somewhere cites the sources of information and materials. With the cost sharing policy in existence, modification of school facilities to 


\section{Ml Macrothink}

mitigate disasters have dragged behind for lack of clarity on who is to do what between the national, county government or the parents. This obviously creates a time lapse in decision making and implementation. There is need for more sensitization on DRR awareness and strategies among the school community otherwise; too many teachers would be having the policy documents but very little skills to actualize them. From the study findings, it is noted that well collected and managed data before a disaster happens, benefits effective preparedness and response and ensures well targeted response to the beneficiaries. Moreover, due to the nature and severity of the disaster at times, backup of information becomes cost-effective and allows a school/ organization to recover quickly from a disaster. This can be efficiently carried out with the help of Ministry of Education data management systems like Education Information Management System (EMIS). Overall, there is a need to establish a culture of safety in schools, that is urgent, and it requires all school communities to understand the risks of disaster unpreparedness and how to reduce threats and try to stimulate a positive mindset in DRR. Disaster risk reduction strategies must be both supply-driven and demand-driven for buying in and to motivate teachers and learners to avoid disasters. This study brings out what the gaps and challenges are in primary schools in Kenya. The findings show that the effectiveness of a school DRR mitigation measures can be a great indicator of how a school and its inhabitants: teachers and children can be prepared or not in times of a disaster.

\section{Recommendations}

The main goal of this research was to evaluate disaster risk reduction preparedness strategies in primary schools in Kenya. Gaps and challenges were noted that required urgent and proactive strategies: map out all the risks in schools, design contextualized and cost disaster risk reduction implementation programs and plans for different scenarios and regions that are cost effective and have a cost sharing framework. Information is power, but only when it is used and accompanied by implementable actions. Provision of policies and policy guidelines is not a panacea to disasters; dissemination and implementation and timely budget allocations are important. Teachers are important stakeholders in mitigation of disasters if they are well prepared and infrastructural development is designed and developed well. Preparing teachers and proactively checking on the infrastructure is not a one -time activity but should be a process as new and more challenging disasters may keep evolving.

\section{Notes}

Note 1. ISDR (2012). Assessing School Safety from Disasters. A Global Baseline Report

Note 2. Gichuhi Loise (2021): Challenges of Covid-19 and Online learning on Children in the Informal Settlements of Nairobi: Parents' Perspectives Journal of the Kenya National Commission for UNESCO, Vol. 1 (1) January-June 2021

Note 3. United Nations (UN), Universal Declaration of Human Rights (New York, 1948)

Note 4. Fires in schools; retrieved on August 2nd 2021 from https://www.accreditedschoolsonline.org/resources/emergency-preparedness-in-school/

Note 5. A head teachers voice in a seminar in Nairobi 
Note 6. Safety Standards Manual: retrieved on 13th August 2021 from http://cwsglobal.org

Note 7. Education Circular No G9/1/169: retrieved on 3rd August 2021 from https://core.ac.uk

Note 8. Safety Standards Manual: retrieved on 13th August 2021 from http://cwsglobal.org

Note 9. Survivor's tears flow 12 years after Bombolulu tragedy retrieved on 3rd August 2021 from

https:/www.standardmedia.co.ke/billow-kerrow/article/2000021929/survivors-tears-flow-12years-after-bombolulu-tragedy

Note 10. List of worst school fires in Kenya: retrieved on 3rd August 2021 from https://nairobinews.nation.co.ke/news/worst-school-fires-in-kenya

Note 11. List of worst school fires in Kenya: retrieved on 3rd August 2021 from https://nairobinews.nation.co.ke/news/worst-school-fires-in-kenya

Note 12. List of worst school fires in Kenya: retrieved on 3rd August 2021 from https://nairobinews.nation.co.ke/news/worst-school-fires-in-kenya

Note

13.

https://www.standardmedia.co.ke/entertainment/local-news/2001253346/sad-seven-students-

dead-in-fire-tragedy-at-moi-girls-nairobi

Note 14. ibid

Note 15. Education: From disruption to recovery; retrieved on August 2nd 2021 from https://en.unesco.org/covid19/educationresponse

Note 16. Impact of covid-19 to children education in Africa; retrieved on August 2nd 2021 from https://www.hrw.org/news/2020/08/26/impact-covid-19-childrens-education-africa

Note 17. Impact of covid-19 to children education in Africa; retrieved on August 2nd 2021 from https://www.hrw.org/news/2020/08/26/impact-covid-19-childrens-education-africa

Note 18. Global Education Coalition Retrieved on 4th August 2021

Note 19. One year into COVID: Prioritizing education recovery to avoid a generational catastrophe retrieved on August 4th 2021 from https://en.unesco.org/news/one-year-covid-prioritizing-education-recovery-avoid-generationa 1-catastrophe

Note 20. Gichuhi Loise (2021): Challenges of Covid-19 and online learning on Children in the Informal Settlements of Nairobi: Parents' Perspectives. Journal of the Kenya National Commission for UNESCO Vol. 1 (1) January-June 2021

Note 21. Improving disaster response efforts through data https://expectexceptional.economist.com/improving-disaster-response-efforts-through-data.ht $\mathrm{ml}$ 
Note 22. Improving disaster response efforts through

datahttps://expectexceptional.economist.com/improving-disaster-response-efforts-through-dat a.html

Note 23. Safety Standards Manual for Schools in Kenya (2008

Note 24. National school re-entry guidelines

Note 25. Kenya Basic Education COVID-19 Emergency Response Plan (May 2020) https://www.education.go.ke

Note 26. Guidelines on Health and Safety Protocols for Reopening of Basic Education Institutions amid COVID-19 Pandemic (September 2020)

Note 27. National school re-entry guidelines

Note 28. Basic Education COVID-19 Emergency Response Plan (May 2020) https://www.education.go.ke

Note 29. Guidelines on Health and Safety Protocols for Reopening of Basic Education Institutions amid COVID-19 Pandemic (September 2020)

Note

30.

https://www.theeastafrican.co.ke/tea/news/east-africa/7-pupils-die-after-classroom-collapses-i n-kenyan-school-1427802

Note 31. ibid

Note 32. https://www.bbc.com/news/world-africa-51373110

Note 33. Safety Standards Manual http://cwsglobal.org

\section{References}

Action Aid, (2007). Lessons for Life -Building a Culture of Safety and Resilience to Disasters through Schools. http://www.preventionweb.net/go/4439

Amenya, D., Fitzpatrick, R., Njeri Mvungu, E.., Naylor, R., Page, E., and Riggall, A. (2021). The Power of Girls Reading Camps: Exploring the impact of radio lessons, peer learning and targeted paper-based resources on girls' remote learning in Kenya. [Working Paper 32]. EdTech Hub. https://doi.org/10.5281/zenodo.4923094

Back, E., Cameron, C., \& Tanner, T. (2009). Children and Disaster Risk Reduction: Taking stock and moving forward. Children in a Changing Climate Research, UNICEF, p20.

Basori. (2013). Utilization of the "EDMODO" social learning network in helping with lectures on automotive body theory in the PTM JPTK study program FKIP UNS. JIPTEK 6(2), p.100. Disaster Risk Reduction in Education in Emergencies: A Guidance Note for Education Clusters and Sector Coordination Groups,

Gichuhi Loise (2021): Challenges of Covid-19 and online learning on Children in the Informal Settlements of Nairobi: Parents' Perspectives. Journal of the Kenya National Commission for UNESCO, 1 (1), January-June 2021 


\section{NI Macrothink}

Hill, M., \& Hupe, P. (2014). Implementing public policy: An introduction to the study of operational governance. Sage. https://doi.org/10.1177\%2F0192636507305102

Inter-Agency Network for Education in Emergencies, INEE. (2009). Applying the INEE Minimum Standards to Ensure Disaster Risk Reduction through Education. Simulation session. Tot Workbook Retrieved September 15, 2021 from http://www.preventionweb.net/go/5475

Inter-Agency Network for Education in Emergencies (INEE). (2010). The minimum standard for education: Preparedness, Response, and Recovery. Jakarta: MOC Publishing. Inter-Agency Network for Education in Emergencies (INEE).

Kano, M., \& Bourque, L. B. (2007). Experiences with and preparedness for emergencies and disasters among public schools in California. NASSP Bulletin, 91(3), 201-218.

Ministry of Education (2020). Basic Education COVID-19 Emergency Response Plan (May 2020) Retrieved September 17, 2021 from https://www.education.go.ke

Ministry of Education (2020). Guidelines on Health and Safety Protocols for Reopening of Basic Education Institutions amid COVID-19 Pandemic (September 2020

Ministry of Education. (2020). National School Re-Entry Guidelines Manual.

Ministry of Education. (2008). Safety Standards Manual. Retrieved September 17, 2021 from http://cwsglobal.org

Mutch, C. (2014). The role of schools in disaster preparedness, response and recovery: what can we learn from the literature? Pastoral Care in Education, 32 (1), 5-22.

Norris, E., M. Kidson, P. Bouchal, and J. Rutter. 2014. Doing Them Justice: Lessons from Four Cases of Policy Implementation, 19. London: Institute for Government.

Ozmen, F. (2006). The level of preparedness of the schools for disasters from the aspect of the school principals. Disaster Prevention and Management, 15(3), 383-395. https://doi.org/10.1108/09653560610669873

Stough, L. M., Kang, D., \& Lee, S. (2018). Seven school-related disasters: Lessons for policymakers and school personnel. Education Policy Analysis Archives, 26(100). http://dx.doi.org/10.14507/epaa.26.3698

Teachers in Crisis Contexts Working Group. (2017). Introduction to training for primary school teachers in crisis contexts. New York: INEE. Available at http://www.ineesite.org/en/trainingpack-for-primary-school- teachers-in-crisis-contexts/

The Economist. (2017). Improving disaster response efforts through data. Retrieved October 12 , 2021 from https://expectexceptional.economist.com/improving-disaster-response-efforts-through-data.ht $\mathrm{ml}$

Towards a Culture of Prevention: Disaster Risk Reduction Begins at School: Good Practices and Lessons Learned UN/ISDR, Geneva, Switzerland, 2007. Retrieved October 15, 2021 from http://www.preventionweb.net/go/3920 
UNESCO IIEP. (2012). Integrating conflict and disaster risk into education sector planning

UNISDR. (2008). Disaster Prevention -A Safe Foundation for Full Inclusion, Retrieved November 27, 2021 from http://www.preventionweb.net/go/15281 